\title{
Variations
}

Variations

Revue internationale de théorie critique

18 | 2013

"La poésie est une arme chargée de futur »

\section{Poèmes projectiles}

\section{Kza Han}

\section{OpenEdition}

Journals

Édition électronique

URL : http://journals.openedition.org/variations/623

DOI : 10.4000/variations.623

ISSN : 1968-3960

\section{Éditeur}

Les amis de Variations

\section{Référence électronique}

Kza Han, «Poèmes projectiles », Variations [En ligne], 18| 2013, mis en ligne le 15 mai 2013, consulté le 05 mai 2019. URL : http://journals.openedition.org/variations/623 ; DOI : 10.4000/variations.623

Ce document a été généré automatiquement le 5 mai 2019.

Les ami•e•s de Variations 


\title{
Poèmes projectiles
}

\author{
Kza Han
}

\section{NOTE DE L'AUTEUR}

Photographie d'un casque Kabuto (Japon) datant de l'ère Edo (1603-1868). Nous adressons nos vifs remerciements à la maison Kunsthandel Klefisch GMBH (Cologne) pour sa généreuse autorisation, ainsi qu'à Madame Olivera Kipcic (Frankfurter Allgemeine Zeitung) pour ses précieux renseignements.

\section{Vire-volte}

En zoom,

ce tigre du Mont Blanc de Corée

détourné de sa destinerrance

au bord du lac céleste,

dénaturé de génération en génération

dans une réserve de Chine,

il ne cesse de bondir, rebondir attrapant, rattrapant

les morceaux sanguinolents

balancés d'une camionnette brinquebalante, avant qu'ils ne s'abattent sur le macadam.

\section{En zoom,}

ce tigre du Mont Blanc de Corée

détourné de sa destinerrance

au bord du lac céleste,

dénaturé de génération en génération

dans une réserve de Chine,

il ne cesse de surgir, resurgir jouant, rejouant

avec l'ombre de Li Po en tigre blanc

chevauché par l'Immortel banni sur cette terre 
ravagée par les Pasteurs-du-désert.

En zoom,

ce tigre du Mont Blanc de Corée détourné de sa destinerrance au bord du lac céleste,

dénaturé de génération en génération dans une réserve de Chine, il ne cesse de sauter, sursauter tranché, retranché de son ombre donnée en pâture par l'antique autoestrangement de quelque côté qu'il se tourne.

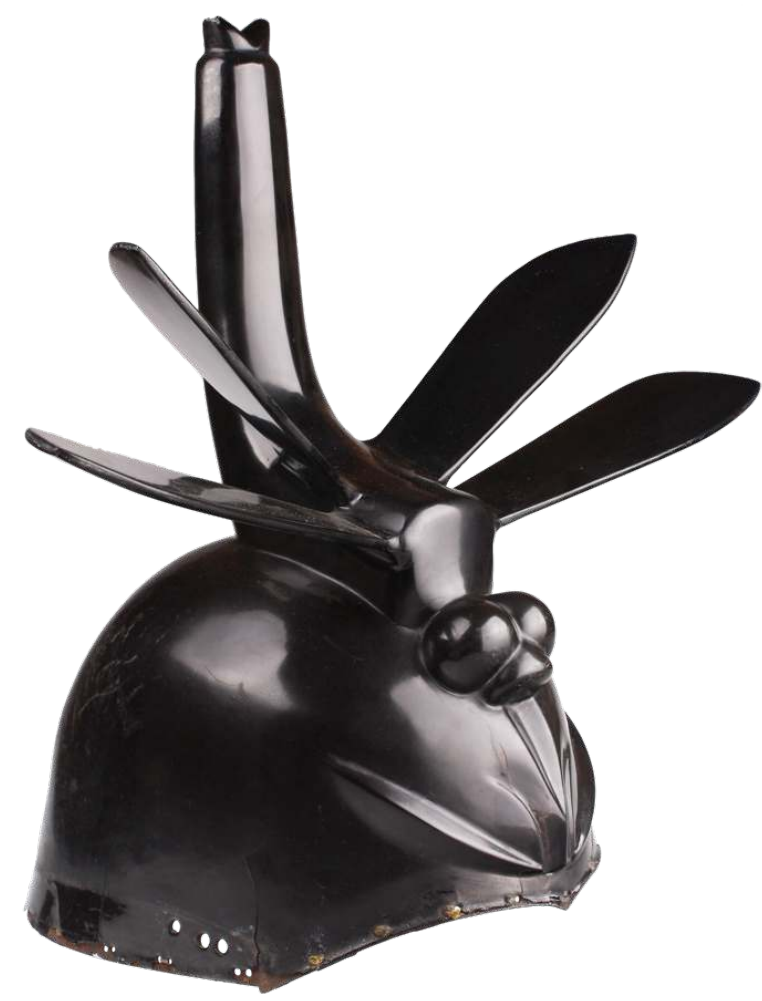

(c) Kunsthandel Klefisch GMBH

\section{Kabuto}

Sur le fil à linge rouillé,

s'agrippant

de ses six pattes graciles, s'éployant

de ses quatre ailes nervurées

laquées de noir veille

à l'aplomb

la libellule d'aurore

du temps d'Edo,

en éveil

ses ocelles de chasseur 
en suspens

son casque de samurai, scrutant

de son double œil

hexagonal

les quatre points cardinaux.

\section{AUTEUR}

\section{KZA HAN}

Kza Han est née en 1942 à Jungup, en Corée. Licence de français à l'Université des Langues étrangères de Corée. Maîtrise de Lettres Modernes sur Samuel Beckett. Apprentissage de l'allemand en compagnie de F. Hölderlin, J. Roth, F. Nietzsche, A. Kluge... Parmi ses publications, Traces erratiques (poèmes en français, allemand, coréen, éditions du Petit Véhicule, Nantes 2007). Vient de paraître : « Douze corps célestes » dans TK-21 n 18, avec douze anaglyphes d'Ekkehart Rautenstrauch en lecture-projection à la Cité des congrès de Nantes le 21 mars 2013. 